\title{
Pamukkale/Hierapolis dünya miras alanı'nda ziyaretçi taşıma kapasitesinin belirlenmesi
}

\author{
Determination of visitor carrying capacity in Pamukkale/Hierapolis world heritage \\ site
}

\section{Veysel DAĞ, Sibel MANSUROĞLU}

Akdeniz Üniversitesi, Ziraat Fakültesi, Peyzaj Mimarlığı Bölümü, 07070, Antalya, Türkiye

Sorumlu yazar (Corresponding author): V. Dağ, e-posta (e-mail): veyseldag@akdeniz.edu.tr Yazar(lar) e-posta (Author e-mail): smansur@akdeniz.edu.tr

\section{MAKALE BİLGİSI}

Alınıs tarihi 16 Kasım 2017

Düzeltilme tarihi 01 Haziran 2018

Kabul tarihi 21 Haziran 2018

\section{Anahtar Kelimeler:}

Fiziksel taşıma kapasitesi

Sosyal taşıma kapasitesi

Dünya miras alanı

Pamukkale

Denizli

\begin{abstract}
ÖZ
Türkiye ve Dünya'da önemli bir yere sahip olan Denizli/Pamukkale'de bulunan Pamukkale/Hierapolis Dünya Miras Alanı, Özel Çevre Koruma Bölgesi, 1. Derece Arkeolojik ve Doğal Sit, Dünya Miras Alanı ve Sulak Alan gibi farklı koruma statüleri altında korunmaktadır. Buna rağmen koruma çalışmalarının etkinliğinde bazı sorunlar ortaya çıkmaktadır. İçerdiği koruma değerleri yanında turizm ve rekreasyon açısından ulusal ve uluslararası boyutta önem taşıyan alanın sürdürülebilir kullanımı yönünde çalıșmalar yapılması önem taşımaktadır. Bu çalışmada yılda yaklaşık 2 milyon kişinin ziyaret ettiğ Pamukkale/Hierapolis Dünya Miras Alanı traverten bölgesinde ziyaretçilere yapılan anket çalışması aracılı̆̆ ile fiziksel ve sosyal taşıma kapasiteleri hesaplanmıştır. Üç farklı yol ve beş farklı grup yoğunluğu için ayrı ayrı hesaplanan fiziksel taşıma kapasitesinin yolların özelliklerine göre sosyal taşıma kapasitesinin ise yaz ve kış dönemine göre farklılık gösterdiğ saptanmıştır. Alanda fiziksel taşıma kapasitesi aşımı hipotezi kısmen doğrulanmış, sosyal taşıma kapasitesi (2 kat) ve fiziksel taşıma kapasitesi (\% 10) değerlerine göre mevcut ziyaretçi sayısının fazla olduğu ve alanda yaşanan sorunların aşırı ziyaretçi sayısı ile ilişkili olduğu anlaşılmıştır. Sonuçta alandaki bozulmaların en aza indirgenmesine, koruma kullanma dengesinin kurulmasına, sürdürülebilirliğinin ve ziyaretçi memnuniyetinin sağlanmasına katkı sağlayacak bazı önlem ve öneriler sunulmuştur.
\end{abstract}

\section{ARTICLE INFO}

Received 16 November 2017

Received in revised form 01 June 2018 Accepted 21 June 2018

\section{Keywords:}

Physical carrying capacity

Social carrying capacity

World heritage site

Pamukkale

Denizli

\begin{abstract}
Pamukkale/Hierapolis World Heritage Site which is selected as the study area is located in Denizli/Pamukkale. The area is very important for both Turkey and the World and protected under various protection statues such as Specially Protection Area, 1st Degree Archeological and Natural Site, World Heritage Site and Wetland. Despite to these protection statues, there are some problems regarding the protection of the area. In this study, it was determined the physical and social carrying capacities, through user questionnaire, of Pamukkale/Hierapolis World Heritage Site, which is visited by approximately 2 million people per year. Physical carrying capacity, which is determined separately for three different routes and five different group intensities, varies according to the characteristics of the routes. Social carrying capacity differs according to the summer and winter periods. The physical carrying capacity overflow hypothesis has been partially confirmed. The number of existing visitors is higher than the social carrying capacity ( 2 times) and the physical carrying capacity $(10 \%)$, and the problems experienced in the field is related with the excessive number of visitors. As a result, some measures and suggestions that will contribute to the reduction of the disruptions in the area, the establishment of the protection use balance, and the maintenance of sustainability and visitor satisfaction have been proposed.
\end{abstract}

\section{Giriş}

Dünyada yaklaşık 100 yıldır park ve korunan alanların rekreasyon amaçlı kullanımının ekosistem üzerindeki etkileri ile ziyaretçi kullanımına nerede ve nasıl müdahale edileceği tartışılmaktadır (Cole 2004). 
Doğal kaynaklara bağlı taşıma kapasitesi kavramı, ilk olarak alan kullanımlarının dă̆glımı ve yaban hayatı alanlarının yönetimi ile gelişmiştir. $\mathrm{Bu}$ kavram bir organizmanın bulunduğu fiziksel koşullar altında yaşamını sürdürüp sürdüremeyeceği temeline dayanmakta olup, alanın sürdürülebilirliğinin sağlanması ve popülasyon sayıs1 çalışmalarında ele alınmıştır (McCool ve Lime 2001; Manning 2007).

Nüfus, biyoloji ve uygulamalı ekolojiye dayanan taşıma kapasitesi kavramı, ilk kez 1922 yılında mera yönetimi, ardından çevre bilimleri ve sosyal bilimler ile turizm ve rekreasyon faaliyetlerinin yönetimi çalışmalarında kullanılmıştır (Clarke 2002; Kurhade 2013). Milli parkların yönetimi ve dış mekan rekreasyon faaliyetlerine bağlı taşıma kapasitesi hesaplamaları 1960'lı yıllara kadar yapılamamıştır (McCool ve Lime 2001). Korunan alanlarda fazla sayıda ziyaretçi olması, doğal kaynakların daha hızlı tahrip edilmesini ve ziyaretçi memnuniyetsizliğini ortaya çıkarmaktadır (Manning 2007). Milli parklarda, doğal kaynak sınırları ve ziyaretten kaynaklanan insan etkilerinin belirlenmesi çalışmalarında, alanın biyofiziksel özellikleri, sosyal faktörler ve yönetim politikaları göz önünde tutulmalıdır (Prato 2001).

Taşıma kapasitesi konusunda birden fazla tanım yapılmakla birlikte, Dünya Turizm Örgütü taşıma kapasitesini "herhangi bir yerde konaklayan ziyaretçilerin yüksek düzeyde memnuniyetini sağlayan ve kaynaklarda düşük düzeyde etkilere yol açan ziyaretçi seviyesi" olarak tanımlamaktadır (Lindberg ve ark. 1996; UNEP 1997).

Çalışmanın özelliklerine bağlı olarak taşıma kapasitesinin farklı boyutları bulunmaktadır. Fiziksel taşıma kapasitesi bir alanda bulunabilecek maksimum sayıdaki insan veya ekipman; ekolojik taşıma kapasitesi bir alan ya da ekosistemin, ekolojik değerleri üzerinde kabul edilemez veya düzeltilemez etkiler oluşmadan yüklenebileceği maksimum rekreasyon kullanım düzeyi; sosyal taşıma kapasitesi ziyaretçilerin deneyim kalitesinde kabul edilemez bir düşme olmadan ve bölge toplumunda kabul edilemez olumsuz bir etki yaşanmadan, bölgenin rekreasyonel aktivitelerin tür ve sayıları açısından kaldırabileceği en yüksek kullanım seviyesi; ekonomik taşıma kapasitesi ise alan yönetimi bakımından kaynak kullanımı ve fayda-maliyet arasındaki en iyi dengenin kurulduğu kapasitedir (Saveriades 2000). Ceballos-Lascurian (1996) rekreasyonel taşıma kapasitesini turist etkinlikleri ile ilişkilendirerek, turizm taşıma kapasitesi şeklinde tanımlamış ve biyofiziksel, sosyokültürel, psikolojik ve yönetimsel olarak dört başlikta ele almıştır. Tanımlardan da anlaşılacağı üzere başta $A B D$ ve Avrupa'nın bazı kentleri olmak üzere ülkemizde de 1960'lı yılların ortalarından günümüze gelişen düşünceler ve yöntemler çerçevesinde, milli parklar (Prato 2001; Lawson ve ark. 2003; Manning ve ark. 2003; Sayan ve ark. 2005; Göktuğ 2011; RiosJara ve ark. 2013; Chen ve ark. 2014), kent ormanları (Fleishman ve Feitelson 2009), sahiller/kıyı alanları (Saveriades 2000; Simon ve ark. 2004; Silva ve ark. 2007; Maggi ve Fredella 2011; Zacarias ve ark. 2011; Yıldırım 2012; Jurado ve ark. 2013), su sporu alanları (Tarrant ve English 1996; Sterl ve ark. 2004) ve diğer korunan alanlarda (Müderrisoğlu 2002; Leujak ve Ormond 2007; Prato 2009; Yang ve ark. 2014) olmak üzere farklı araştırmacılar tarafından taşıma kapasitesi analizleri yapılmıştır. Tarihi ve kültürel korunan alanlar (Tokmak 2008; Manning ve ark. 2002) ve doğal özelliklere sahip Dünya Miras Alanı (Turton 2005) ile ilgili yapılmış taşıma kapasitesi çalışmaları bulunurken, karma (doğal/kültürel) Dünya Miras Alanı ile ilgili yapılmış herhangi bir çalışmaya rastlanamamıştır.
Turizm ve rekreasyon için kullanılan korunan alanlarda taşıma kapasitesi tabanlı, geliştirilen ziyaretçi yönetim modelleri Kabul Edilebilir Değişim Sınırları (LAC), Ziyaretçi Etkinliği Yönetim Süreci (VAMP), Ziyaretçi Etki Yönetimi (VIM), Rekreasyonel Olanakların Dağılımı (ROS), Ziyaretçi Deneyimini ve Kaynak Koruma (VERP), Turizm Optimum Yönetim Modeli (TOMM) ve Ziyaretçi Kapasitesi Görev Gücü (VCTF)'dür (Lindberg ve ark. 1996; Eagles ve ark. 2002; Haas 2002; Prato 2009).

$\mathrm{Bu}$ çalışmanın amacı Pamukkale/Hierapolis Dünya Miras Alanı'nda en etkin kullanım olan turizm ve rekreasyon faaliyetleri bağlamında taşıma kapasitesinin belirlenmesidir. Bu amaçla ziyaretçilere yönelik yapılan anket çalışması ile korunan alanlarda kullanılan ziyaretçi taşıma kapasitesi (Fiziksel ve Sosyal Taşıma Kapasiteleri) hesaplanarak, yapılan değerlendirmeler ile anket ve sonuçları dikkate alınarak, Pamukkale/Hierapolis Dünya Miras Alanı'nda koruma/ kullanma dengesinin kurulmasına, alanın sürdürülebilirliğinin ve ziyaretçi memnuniyetinin sağlanmasına katkı sağlayacak bazı önlem ve öneriler geliştirilmiştir.

\section{Materyal ve Yöntem}

\subsection{Materyal}

Çalışmanın ana materyalini Denizli il merkezinin $20 \mathrm{~km}$ kuzeybatısında bulunan Pamukkale Özel Çevre Koruma Bölgesi içerisinde yer alan Pamukkale/Hierapolis Dünya Miras Alanı olan ören yeri oluşturmaktadır. Yaklaşık $27180 \mathrm{~m}^{2}$ alana sahip ören yeri içerisinde giriş $\left(1382 \mathrm{~m}^{2}\right)$, otopark $\left(1936 \mathrm{~m}^{2}\right)$, seyir terası $\left(2282 \mathrm{~m}^{2}\right)$, açık alan $\left(1067 \mathrm{~m}^{2}\right)$, yeşil alan $\left(500 \mathrm{~m}^{2}\right)$, termal su kaynaklar1/antik havuz $\left(500 \mathrm{~m}^{2}\right)$, traverten sahas1 $\left(7763 \mathrm{~m}^{2}\right)$, arkeolojik sit alanı $\left(11150 \mathrm{~m}^{2}\right)$ ve müze $\left(600 \mathrm{~m}^{2}\right)$ gibi kullanımlar yer almaktadır (Şekil 1).

Çalışma alanı olan Pamukkale/Hierapolis Dünya Miras Alanı çevresi ile birlikte başlangıçta orman rejimine alınarak her türlü yapılaşma ve kaynakların yanlış kullanımından korunmak istenmiş ve Gayrimenkul Eski Eserler ve Anıtlar Yüksek Kurulu'nun (GEEAYK) 13.12.1980 tarih ve A-2587 sayll kararı ile "I. Derece Arkeolojik ve I. Derece Doğal Sit Alanı" olarak ilan edilmiştir. 22.10.1990 tarih ve 90/1117 sayılı Bakanlar Kurulu Kararı ile "ekolojik öneme sahip, çevre kirlenmesine ve bozulmaya hassas, tarih ve tabiat varlikları bulunan alanların gelecek nesillere intikalini sağlamak, getirilecek koruma ve gelişme kararları ile bu vasıflarının devamlılığını temin etmek amacıyla" 6656 ha'lık alan "Özel Çevre Koruma Bölgesi” olarak tespit ve ilan edilmiştir (Resmi Gazete 1990). Ayrica bölge, 09.12.1988 tarih ve 485 no ile UNESCO'nun Dünya Kültürel ve Doğal Mirasının Korunması Sözleşmesi uyarınca doğal ve kültürel değerleri nedeniyle "Dünya Miras Listesi”ne alınmıştır. Ancak geçen süre içerisinde alanın iyi korunamaması ve koruma çalışmalarında yaşanan sorunlar ile travertenlerin aşırı kirlenmesi nedeniyle 1998 yılında Dünya Miras Alanı Listesi'nden çıkarılması gündeme gelmiştir. Doğa Koruma ve Milli Parklar Genel Müdürlüğü'nün yapmış olduğu çalışmalar sonucu alan aynı zamanda "Sulak Alan" olarak ilan edilmiştir (Çevre ve Şehircilik Bakanlığ 1 2014; Doğa Koruma ve Milli Parklar Genel Müdürlüğü 2014; Kültür ve Turizm Bakanlığı 2014; UNESCO 2014).

Pamukkale/Hierapolis Ören Yeri 2015 yılı ziyaretçi istatistikleri siralaması temel alındığında ziyaret sayısı (1 731271 ziyaret) ve gelir (28 692725 TL) durumuna göre ülkemizdeki ören yerleri sıralamasında 4. sırada yer almaktadır (DÖSIMM 2016). Pamukkale/Hierapolis Ören Yeri'nin 2000- 


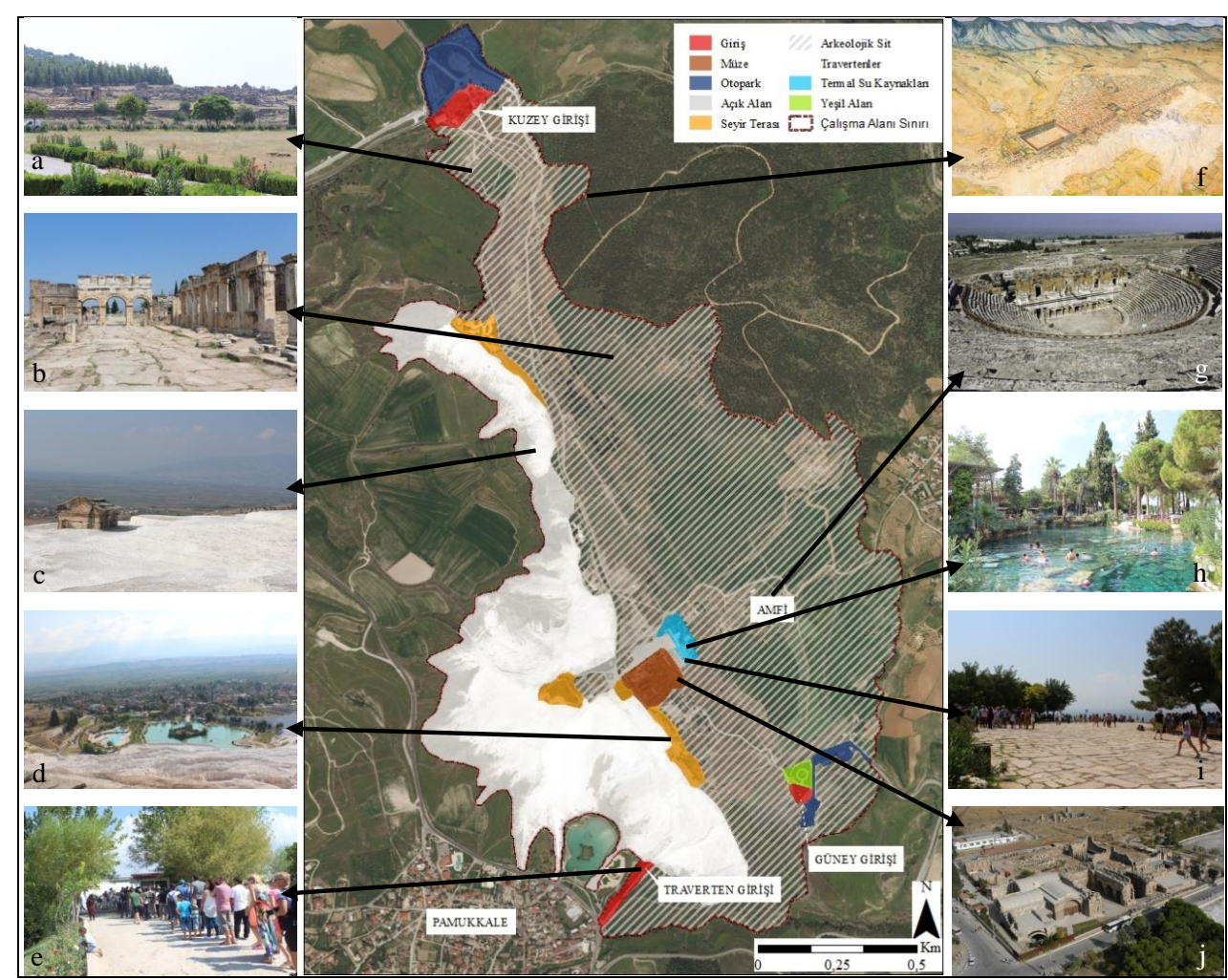

Şekil 1. Çalışma alanı ve içerisinde bulunan bazı kullanımlar (a-Nekropol Alanı, b-Frontinus Kapısı, c-Anıt Mezar, d-Pamukkale, e-Traverten Girişi, f-Hierapolis Antik Kent Yerleşim Modeli, g-Amfi Tiyatro, h-Antik Havuz, i-Açık Alan, j-Müze).

Figure 1. Study area and some land uses (a-Nekropol, b-Frontinus Gate, c-Tomb, d-Pamukkale, e- Entrance of Travertine, f-Hierapolis, g-Theatre, hAntik Pool, i-Square, j-Museum).

2015 yılları arasında ziyaret sayısı bazı dönemlerde (2003, 2006, 2009, 2015) bir önceki yıla göre düşüş gösterse de çoğunlukla artmıştır. Türkiye genelindeki ören yerleri ile karşılaştırma yapıldığında toplam ziyaret ortalamasının \% 6.73 olduğu görülmektedir (Çizelge 1). Bu durum alanın, ulusal ve uluslararası anlamda önemli bir turizm bölgesi olduğunu ve ülke ekonomisine önemli katkı sağladığını göstermektedir.

Araştırma alanında fiziksel ve sosyal taşıma kapasitelerinin belirlenmesine yönelik yerli ziyaretçilere anket uygulanmıştır. Anket, bireylerin demografik yapısı ve Pamukkale/Hierapolis Dünya Miras Alanı'nda ziyaretçi davranışları hakkındaki görüşlerin saptanması yönünde yapılandırılmış olup, anketlerden elde edilen verilerden de materyal olarak yararlanılmıştır.

\subsection{Yöntem}

Pamukkale/Hierapolis Dünya Miras Alanı'nda yürütülen araştırma, arazi ve ofis olmak üzere iki yönde ve üç aşamalı olarak yürütülmüştür.

Araştırmanın ilk aşamasında çalışma alanında en etkin kullanım olan turizm ve rekreasyon faaliyetlerinin kapsamının belirlenmesi amaciyla, Pamukkale/Hierapolis Ören Yeri Yaya Girişi (Traverten Bölgesi)'nde alanı ziyaret eden yerli turistlere yönelik, standart formlar aracılığıyla, yerinde, karşılık görüşme yolu ile yapılandırılmış anket uygulanmıştır. Anket, alanı farklı dönemlerde (Temmuz 2015 ve Ekim 2015 aras1) ziyaret edenler içerisinden, rastlantısal seçim yöntemi ile belirlenen kişilere uygulanmıştır. Örnekleme büyüklüğünün saptanmasında Arkin ve Colton'un \% 5 hata payına göre 100000 'nin üzerindeki nüfus için öngördüğü en az 400 kişi sayısı temel alınmıştır (Pulido 1972). Anket soruları hazırlanırken, çalışmada kullanılan istatistiksel analiz yöntemlerine uygunluğu dikkate alınmıştır.

Çizelge 1. Pamukkale/Hierapolis ve ülkemizdeki ören yerlerinin yıllık ziyaret sayısı (Denizli İl Kültür ve Turizm Müdürlüğü (2015) ve DÖSIMMM (2016)'den yararlanarak).

Table 1. Number of visitors to Pamukkale and Turkey's archaeological sites in the period of 2000-2015.

\begin{tabular}{|c|c|c|c|c|}
\hline \multirow[b]{4}{*}{ Y1l } & \multirow{4}{*}{$\begin{array}{c}\text { Türkiye Ören } \\
\text { Yerleri Ziyaret } \\
\text { Sayisı }\end{array}$} & \multicolumn{2}{|c|}{$\begin{array}{c}\text { Pamukkale-Hierapolis } \\
\text { Ören Yeri Yıllık Ziyaret } \\
\text { Sayısı }\end{array}$} & \multirow{4}{*}{$\begin{array}{l}\text { Pamukkale- } \\
\text { Hierapolis Ören } \\
\text { Yeri Günlük } \\
\text { Ortalama } \\
\text { Ziyaret Sayısı }\end{array}$} \\
\hline & & & Ülke & \\
\hline & & & Geneline & \\
\hline & & Toplam & Oranı $(\%)$ & \\
\hline 2000 & 6887344 & 839264 & 12.18 & 2299 \\
\hline 2001 & 7590138 & 1107214 & 14.58 & 3033 \\
\hline 2002 & 14268186 & 1152000 & 8.07 & 3156 \\
\hline 2003 & 13987747 & 999650 & 7.14 & 2738 \\
\hline 2004 & 13015486 & 1260250 & 9.68 & 3452 \\
\hline 2005 & 18384865 & 1358500 & 7.38 & 3721 \\
\hline 2006 & 16086050 & 993400 & 6.17 & 2721 \\
\hline 2007 & 18048674 & 1153410 & 6.39 & 3160 \\
\hline 2008 & 22662590 & 1408213 & 6.21 & 3858 \\
\hline 2009 & 21193627 & 1323961 & 6.24 & 3627 \\
\hline 2010 & 25854341 & 1495046 & 5.78 & 4096 \\
\hline 2011 & 28462893 & 1713695 & 5.95 & 4695 \\
\hline 2012 & 28781308 & 1612723 & 5.60 & 4418 \\
\hline 2013 & 29481005 & 1699772 & 5.76 & 4656 \\
\hline 2014 & 29774390 & 1875000 & 6.29 & 5136 \\
\hline 2015 & 28114252 & 1731271 & 6.15 & 4743 \\
\hline Ortalama & 20162056 & 1357710 & 6.73 & 3719 \\
\hline
\end{tabular}


Anket, tek seçenekli, çok seçenekli, açık uçlu ve katılım düzeyi olmak üzere 4 soru tipi içermekte olup, iki bölümden oluşmaktadır. Anketin I. bölümünde ziyaretçilerin demografik özellikleri (11 madde), II. bölümünde ise Pamukkale/Hierapolis Dünya Miras Alanı hakkındaki görüşleri (26 madde) toplam 37 madde ile sorgulanmıştır. Ziyaretçilerin alan ile ilgili görüşlerini daha kolay ifade edebilmeleri ve çalışmanın hedefine yönelik II. bölümdeki ifadeler 5'li likert ölçeği, çoktan seçmeli, açık uçlu ve sıralama ölçütlü olarak oluşturulmuştur.

Çalışmanın ikinci aşamasında anket çalışmasından elde edilen verilerden bazıları ile aşağıda sunulan formüller kullanılarak, Pamukkale/Hierapolis Dünya Miras Alanı'nda doğal ve kültürel değerlerin korunmasına katk1 sağlaması açısından önem taşıyan, IUCN tarafindan önerilen (CeballosLascurian 1996), Fiziksel Taşıma Kapasitesi (FTK) ve Sosyal Taşıma Kapasitesi (STK) hesaplamaları yapılmıştır. Aşağıda sunulan formüller Sayan ve ark. (2005), Göktuğ (2011) ve Soylu (2013) tarafindan da kullanılmıştır. Fiziksel Taşıma Kapasitesi ve Sosyal Taşıma Kapasitesi hesaplanan yolların belirlenmesinde Nisan 2015-Mayis 2016 döneminde toplam 60 gün süresince yapılan gözlemler, ilgili kişiler ve yöre halkı ile yapılan görüşmeler etkili olmuştur.

Fiziksel Taşıma Kapasitesi: Tanımlanmış bir mekan içine, belirli bir zamanda fiziksel olarak sığabilen maksimum insan sayısıdır ve aşağıdaki gibi formüle edilmiştir.

$$
F T K=A \times Z / a \times R f
$$

\section{FTK: Fiziksel Taşıma Kapasitesi}

A: Alan (Ziyaretçi kullanımı için mevcut alan $\left(\mathrm{m}^{2}\right)$ veya yol uzunluğu (m))

Z/a: Ziyaretçi/alan (Ziyaretçi başına düşen alan miktarı (ziyaretçi $/ \mathrm{m}^{2}$ ) veya yol uzunluğu (ziyaretçi $\left./ \mathrm{m}\right)$ )

Rf (Rotasyon faktörü): Çalışma saatleri içerisinde bir alanda izin verilebilen ziyaret sayısıdır. Alanın günlük açık olduğu süre / bir ziyaretin ortalama süresi formülü ile hesaplanmıştır.

Sosyal Taşıma Kapasitesi: Ziyaretçilerin bir alanda karşılaşmayı istedikleri en fazla kişi ya da grup sayısı olup, her alanın ziyaretle ilgili belirli özelliklerine göre değişiklik gösterebilecek bir değeri ifade etmektedir. $\mathrm{Bu}$ değerin hesaplanmasında aşağıda açıklanan formül kullanılmıştır.

$$
S T K=G K s \times R f
$$

STK: Sosyal Taşıma Kapasitesi

GKs: Karşıllaşılması İstenen En Fazla Grup veya Kişi Sayısı (ortalama)

Rf (Rotasyon Faktörü): FTK hesaplamasında kullanılan Rf kullanılmıştır.

Çalışmanın son aşamasında ise ilk iki aşamadan elde edilen veriler ışığında, araştırma alanındaki çevresel etkiler ile taşıma kapasitesine bağlı değerlendirmeler, anket sonuçları dikkate alınarak, neden-sonuç ilişkisi bağlamında Pamukkale/Hierapolis Dünya Miras Alanı'nda peyzaj yönetimi kapsamında koruma/kullanma dengesinin kurulmasına katkı sağlayacak bazı önlem ve öneriler geliştirilmiştir.

\section{Bulgular ve Tartışma}

\subsection{Ziyaretçi ve alan özellikleri}

Pamukkale/Hierapolis Dünya Miras Alanı Ören Yeri ziyaretçilerinin \% 66's1 erkek, \% 55.7'si bekar, \% 43'ü 18-24 yaş aralığında, \% 37'si (eşit) lise ve üniversite mezunu, \% 24'ü 2001-3000 TL gelire sahip ve \% 35.7'si öğrencidir (Çizelge 2).

Anket sonuçlarından elde edilen, fiziksel ve sosyal taşıma kapasitelerinin hesaplanmasinda kullanılan, alanda olmas1 gereken kiși, alanda harcanan süre, tanımadığ arasında olmasını istediği mesafe ile ilgili ayrıntılar Çizelge 3 'te sunulmuştur.

Pamukkale/Hierapolis Ören Yeri'ne gelen ziyaretçiler alanı 3 farklı (Kuzey Kapısı, Güney Kapısı, Traverten Bölgesi Yaya Girişi) giriş kapısından ziyaret etmektedirler. $\mathrm{Bu}$ girişlerden ören yeri içerisinde farklı yoğunluk ve uzunluklara göre ziyaretçilerin en fazla kullandıkları 3 yol belirlenmiştir. Bu yollar, kullanım yoğunluklarına göre traverten bölgesi yaya girişinden traverten bölgesinde bulunan dinlenme alanına kadar

Çizelge 2. Ankete katılan ziyaretçilerin demografik özellikleri $(\mathrm{n}=400)$.

\begin{tabular}{|c|c|c|c|c|c|c|c|}
\hline Yaş Grubu & $(\%)$ & Ĕgitim düzeyi & $(\%)$ & Gelir (TL) & $(\%)$ & Meslek & $(\%)$ \\
\hline $18-24$ & 43.0 & İlkokul & 3.8 & 1000 'den az & 7.5 & Memur & 21.3 \\
\hline $25-34$ & 27.8 & Ortaokul & 11.8 & $1001-2000$ & 21.5 & İşçi & 3.7 \\
\hline $35-44$ & 14.8 & Lise & 37.0 & $2001-3000$ & 24.0 & Çiftçi & 0.8 \\
\hline $45-54$ & 9.0 & Yüksekokul & 3.5 & $3001-4000$ & 13.0 & Emekli & 3.0 \\
\hline $55-64$ & 4.5 & Üniversite & 37.0 & $4001-5000$ & 10.3 & İşsiz & 3.3 \\
\hline \multirow[t]{4}{*}{+65} & 1.0 & Lisansüstü & 7.0 & +5000 & 23.7 & Öğrenci & 35.7 \\
\hline & & & & & & Özel Sektör & 16.3 \\
\hline & & & & & & Serbest Meslek & 10.0 \\
\hline & & & & & & Diğger & 6.0 \\
\hline
\end{tabular}

Table 2. Respondents' demographic characteristics $(n=400)$.

Çizelge 3. Ziyaretçilerin alanı ziyaret ile ilgili görüşleri.

\begin{tabular}{|c|c|c|c|c|c|}
\hline Olması Gerektiği Düşünülen Kişi Sayısı & $(\%)$ & Harcanan Süre (dk.) & $(\%)$ & Tanımadığı Kişiler ile Arasında Olması İstenen Mesafe & $(\%)$ \\
\hline 10 kişi ve daha az & 1.8 & $10-30$ & 9.5 & 1 m'den az & 18.7 \\
\hline 11-50 kişi & 9.3 & $40-60$ & 43.6 & $1-3 \mathrm{~m}$ & 48.3 \\
\hline 51-100 kişi & 15.7 & $75-120$ & 32.3 & 3-5 m & 23.0 \\
\hline 101-200 kişi & 33.4 & $135-180$ & 11.3 & $5-10 \mathrm{~m}$ & 10.0 \\
\hline 201-500 kişi & 34.7 & $180-360$ & 3.5 & & \\
\hline 501-1000 kişi & 4.3 & & & & \\
\hline + 1001 kişi & 0.8 & & & & \\
\hline
\end{tabular}

Table 3. Visitors' perceptions on the site. 
yoğun (623 m), Güney Giriş Kapısı'ndan traverten üst bölgesi ile antik tiyatroya kadar orta yoğun $(2708 \mathrm{~m})$ ve Kuzey Giriş Kapısı'ndan antik tiyatro yol ayrımına kadar az yoğun (1 695 m) olarak sınıflandırılmıştır (Şekil 2).

\subsection{Fiziksel Taşıma Kapasitesi (FTK)}

Çalışma alanında Nisan 2015-Mayıs 2016 döneminde toplam 60 gün süresince yapılan gözlemler, ilgili kişiler ve yöre halkı ile yapılan görüşmeler sonucu belirlenen 3 farklı yol için farklı grup büyüklüklerine göre Fiziksel Taşıma Kapasitesi hesaplanmıştır. Bunun en önemli nedeni yolların farklı yoğunluk ve karakterlerde (yoğun traverten bölgesi, orta yoğun patika+granit küp taş+ahşap, az yoğun patika+granit küp taş) olmasidir.

Anket sonuçlarına göre ziyaretçilerin tanımadığı kişiler ile arasında olmasını istediği mesafe ortalama 2.8 m'dir. Neufert (2012)'te bunun en az $1.75 \mathrm{~m}$ olarak belirtilmesi ve araştırma alanının özellikleri dikkate alınarak, bu mesafe $(1.75 \mathrm{~m})$ kabul edilmiştir. Buna göre 50,100, 150, 200 ve 250 kişilik gruplar için hesaplanan Fiziksel Taşıma Kapasitesinde her bir grubun ihtiyaç duyduğu yol uzunlukları Çizelge 4'te sunulmuştur. Fiziksel Taşıma Kapasitesinin hesaplanması için gerekli olan rotasyon faktörü, alanın yaz ve kış dönemlerinde gün uzunluğuna bağlı resmi ziyaret sürelerinin farklılığından dolayı 2 dönemde ele alınmıştır (Çizelge 4).

Pamukkale/Hierapolis Ören Yeri için hesaplanan Fiziksel Taşıma Kapasiteleri belirlenen yolların özelliklerine bağlı olarak farklılık göstermektedir. Çizelge 5 incelendiğinde yoğunluğu en fazla olan yolun Fiziksel Taşıma Kapasitesi'nin en düşük olduğu görülmektedir. Belirlenen 3 farklı yolun ortalama günlük ziyaret sayısı kış dönemi için 2902 , yaz dönemi için ise 3870 olup, dönem ayrımı yapılmadığı takdirde günlük ortalama ziyaret sayısı 3386 olarak hesaplanmıştır. Bu değer 2000-2015 yılları arasında ortalama günlük ziyaret sayısının (3 719 ziyaret/gün) altında olduğundan, alanın fiziksel taşıma kapasitesinin üzerinde (\% 10) kişi tarafından ziyaret edildiği anlaşılmaktadır.

Ülkemizde Gündüz ve Akpınar (2002) Beynam Muhafaza Ormanı'nda (ortalama 42 kişi/hektar), Müderrisoğlu (2002) Abant Tabiat Parkı'nda (piknik için 1965 kişi/gün, göl etrafı yürüyüş için 2438 kişi/gün ve orman içi yürüyüş için 1313 kişi/gün), Sayan ve ark. (2005) Termessos Milli Parkı'nda (4 650 ziyaret/gün), Soylu (2013) Gelibolu Yarımadası Tarihi Milli Parkı'nda (3 042 ziyaret/gün), Yıldırım (2012) Konyaaltı Plajı'nda (Antalya) (270 aile; 1 aile $=4$ kişi) ziyaretçi sayısına bağlı taşıma kapasitesi hesaplamalarına yönelik araştırmalar yapmışlardır. Ancak bu alanlar fiziksel ve doğal özellikleri ve

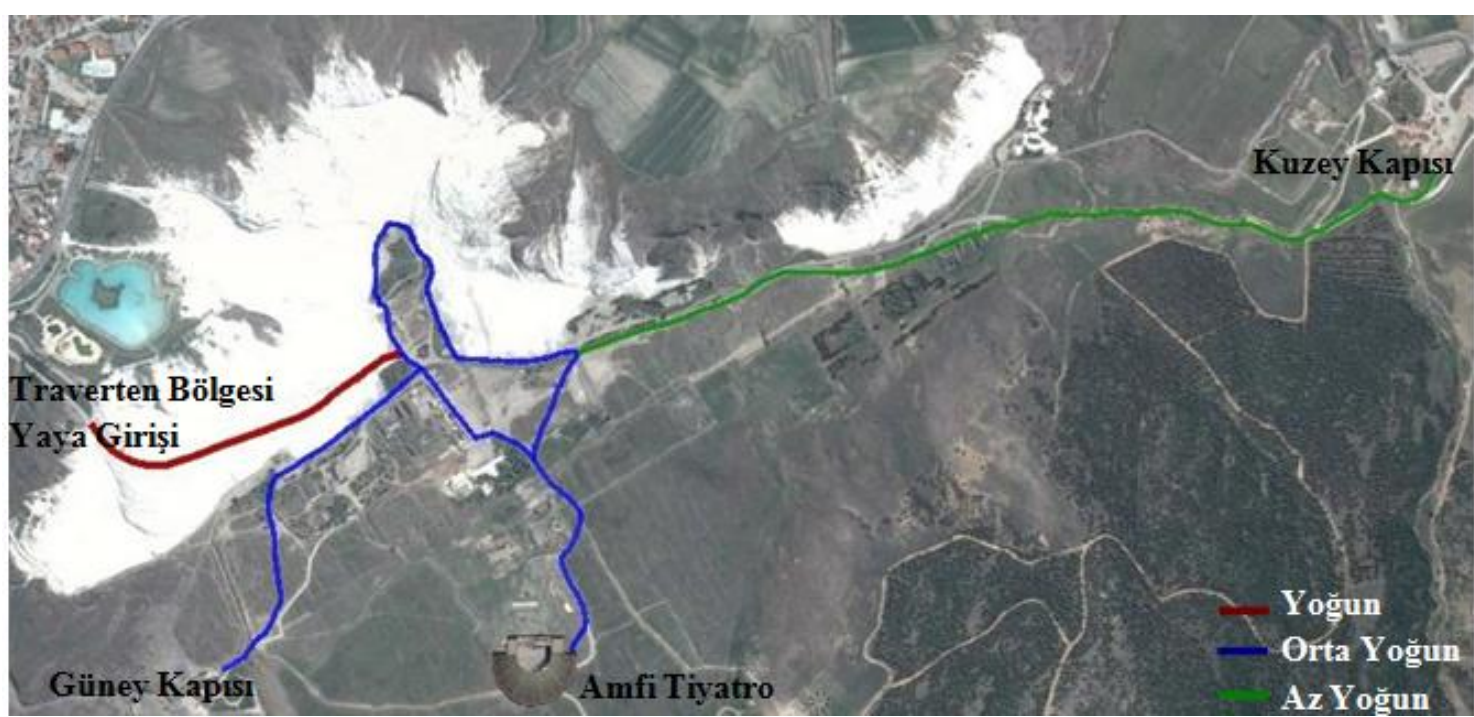

Şekil 2. Yoğunluklarına göre belirlenen yol güzergahları.

Figure 2. Routes determined by their density.

Çizelge 4. Yolların özellikleri.

Table 4. Features of the routes.

\begin{tabular}{|c|c|c|c|c|c|}
\hline Yol Yoğunluğu & & Yoğun & Orta Yoğun & Az Yoğun & Toplam \\
\hline Ziyaretçi akışı & & Çift yönlü & Çift yönlü & Çift yönlü & Çift yönlü \\
\hline 1 kişinin kapladığı doğrusal uzunluk (m) & & 1.75 & 1.75 & 1.75 & 1.75 \\
\hline Yol uzunluğu (m) & & 623 & 2708 & 1695 & 5026 \\
\hline \multirow[t]{2}{*}{ Ören yerinin ziyarete açık olduğu süre (saat) } & Kış dönemi & 9 & 9 & 9 & 9 \\
\hline & Yaz dönemi & 13 & 13 & 13 & 13 \\
\hline Bir ziyaretin ortalama süresi (saat) & & 1.5 & 1.5 & 1.5 & 4.5 \\
\hline \multirow[t]{2}{*}{ Rf (Rotasyon Faktörü-Günlük ziyaret sayısı) } & Kış dönemi & 6 & 6 & 6 & 2 \\
\hline & Yaz dönemi & 8 & 8 & 8 & 3 \\
\hline \multirow{5}{*}{$\begin{array}{l}\text { Ziyaretçi başına düşen yol uzunluğu (Z/a) } \\
\text { (1 ziyaretçi/m) }\end{array}$} & 50 kişilik grup için & $350 \mathrm{~m}$ & $1312.5 \mathrm{~m}$ & $875 \mathrm{~m}$ & $2350 \mathrm{~m}$ \\
\hline & 100 kişilik grup için & $350 \mathrm{~m}$ & $1400 \mathrm{~m}$ & $700 \mathrm{~m}$ & $2400 \mathrm{~m}$ \\
\hline & 150 kişilik grup için & $262.5 \mathrm{~m}$ & $1425 \mathrm{~m}$ & $950 \mathrm{~m}$ & $2400 \mathrm{~m}$ \\
\hline & 200 kişilik grup için & $350 \mathrm{~m}$ & $1400 \mathrm{~m}$ & $700 \mathrm{~m}$ & $2500 \mathrm{~m}$ \\
\hline & 250 kişilik grup için & $437.5 \mathrm{~m}$ & $1312.5 \mathrm{~m}$ & $875 \mathrm{~m}$ & $2500 \mathrm{~m}$ \\
\hline
\end{tabular}


Çizelge 5. Grup büyüklüğüne göre yolların Fiziksel Taşıma Kapasitesi.

Table 5. Physical Carrying Capacity of the routes according to group size.

\begin{tabular}{|c|c|c|c|c|c|}
\hline & & Yoğun & Orta Yoğun & Az Yoğun & Ortalama \\
\hline \multirow{2}{*}{50 kişilik grup için (Ziyaret/gün) } & Kış Dönemi & 1200 & 4500 & 3000 & 2900 \\
\hline & Yaz Dönemi & 1600 & 6000 & 4000 & 3866 \\
\hline \multirow{2}{*}{100 kişilik grup için (Ziyaret/gün) } & Kış Dönemi & 1200 & 4800 & 2400 & 2800 \\
\hline & Yaz Dönemi & 1600 & 6400 & 3200 & 3733 \\
\hline \multirow{2}{*}{150 kişilik grup için (Ziyaret/gün) } & Kıș Dönemi & 900 & 4885 & 3257 & 3014 \\
\hline & Yaz Dönemi & 1200 & 6514 & 4342 & 4018 \\
\hline \multirow{2}{*}{200 kişilik grup için (Ziyaret/gün) } & Kış Dönemi & 1200 & 4800 & 2400 & 2800 \\
\hline & Yaz Dönemi & 1600 & 6400 & 3200 & 3733 \\
\hline \multirow{2}{*}{250 kişilik grup için (Ziyaret/gün) } & Kış Dönemi & 1500 & 4500 & 3000 & 3000 \\
\hline & Yaz Dönemi & 2000 & 6000 & 4000 & 4000 \\
\hline \multirow{2}{*}{ Ortalama } & Kış Dönemi & 1200 & 4697 & 2811 & 2902 \\
\hline & Yaz Dönemi & 1600 & 6262 & 3748 & 3870 \\
\hline
\end{tabular}

kullanım amacı açısından çalışma alanı olan Pamukkale/Hierapolis Dünya Miras Alanı'ndan farklı özelliklere sahiptir. Ayrıca yapılan araştırmalarda fiziksel taşıma kapasitesinin hesaplandığı alanların özelliklerine göre sınıflandırılmadığı ve kış/yaz dönemi ayrımının yapılmadığ görülmüştür. $\mathrm{Bu}$ çalışmada yolların özelliklerine göre FTK'lerinin ayrı ayrı ele alınmasının en önemli nedenlerinden bir tanesi yollardaki ziyaretçi yoğunluğunun ve yol özelliklerin birbirinden farklı olmasıdır. Benzer şekilde Göktuğ (2011) Dilek Yarımadası Büyük Menderes Deltası Milli Parkı'nda botanik parkuru (3 780 kişi/gün), oluklu kanyon (10 157 kişi/gün) ve Eski Doğanbey Köyü Kültür Gezisi Parkuru (2 192 kişi/gün) için fiziksel ve sosyal taşıma kapasitelerini hesaplamış, ancak dönemsel farklılığa göre değerlendirmeler yapmamıştır. Pamukkale/Hierapolis Dünya Miras Alanı ören yerinin yaz ve kış dönemlerinde ziyarete açık olma sürelerinin farklıı̆̆gından dolayı, her dönem için ayrı hesaplamalar yapılmıştır. Ayrıca incelenen birçok araştırmada araştırmacıların fiziksel taşıma kapasitesi ve iklim verilerinden yola çıkarak alanın gerçek taşıma kapasitesi (bir alanda izin verilen maksimum ziyaret sayısı olup, alanın belirli negatif özelliklerinden elde edilen düzeltme faktörlerinin Fiziksel Taşıma Kapasitesinden matematiksel olarak çıkarılmasıyla elde edilir) ile ilgili hesaplamalar yaptıkları görülmüştür. $\mathrm{Bu}$ çalışmada gerçek taşıma kapasitesinin hesaplanmamasının en önemli nedeni alanın yapısal olarak diğer alanlardan farklı (traverten sahası, yer altı/yerüstü su kaynakları, antik kent, bitki ve hayvan varlığı gibi) birçok özelliğe sahip olmasıdır. Alanın sahip olduğu bu hassas yapının sadece ziyaretçi sayısı ve iklim özelliklerinden değil, kentten ve ziyaretçilerden kaynaklanan birçok çevresel ve fiziksel faktörden etkilendiği ve bu konunun ayrıca araştırılması gerektiği düşünülmektedir.

\subsection{Sosyal Taşıma Kapasitesi (STK)}

Sosyal Taşıma Kapasitesi Pamukkale/Hierapolis Ören Yeri'nin alansal olarak en küçük, ancak en yoğun olduğu traverten bölgesi için belirlenmiştir. Sosyal Taşıma Kapasitesi'nin hesaplanmasında öncelikle anket sorularından elde edilen alanda görülmek istenen ortalama kişi sayısı (246 kişi), rotasyon faktörü, ortalama ziyaret süresi (91.5 dakika) ile ören yerinin ziyarete açık olduğu süre (kış-9 saat / yaz-8 saat) temel alınmıştır (kış 5.9 saat / yaz 8.5 saat). Buna göre alanın kış döneminde günlük Sosyal Taşıma Kapasitesi 1451 ziyaretçi, yaz döneminde ise 2091 ziyaretçi olarak hesaplanmıştır.
Kış dönemi STK

$$
\begin{aligned}
& S T K=G K s \times R f \quad S T K=246 \times 5.9 \\
& S T K=1451 \text { ziyaretçi/gün } \\
& \text { Yaz dönemi STK } \\
& S T K=\text { GKs } x \text { Rf STK=246x8.5 } \\
& S T K=2091 \text { ziyaretçi/gün }
\end{aligned}
$$

Sayan ve ark. (2005) Termessos Milli Parkı'nda Sosyal Taşıma Kapasitesini 90 ziyaretçi/gün olarak belirlemişlerdir. Yaz ve kış dönemi için hesaplanan sosyal taşıma kapasitesinden oldukça düşük olan bu değerin, milli park alanının büyüklüğü ve daha az sayıdaki ziyaretçi varlığından kaynaklandığı düşünülmektedir. Pamukkale/Hierapolis Ören Yeri’nin ziyaretçi sayıs1 ve alan büyüklüğü düşünüldüğünde, sosyal taşıma kapasitesinin belirlenmesi ve buna uygun bir ziyaretçi düzeninin kurulması, koruma alanının sürdürülebilirliği açısından gereklidir. Benzer şekilde Jurincic (2005) Slovenya'nın Istria Bölgesi'nde turizme bağlı olumsuz etkilerin azaltılması ve sürdürülebilir turizm çalışmalarının geliştirilmesi için Sosyal Taşıma Kapasitesinin de belirlenmesi gerektiğini önermektedir.

\subsection{Taşıma kapasitesi aşımına bağlı alanda yaşanan sorunlar}

Yapılan araştırmalara göre her rekreasyonel faaliyetin çevre üzerinde farklı derecelerde olumsuz etkilere yol açabileceği tespit edilmiştir (Salerno ve ark. 2013; Eagles ve ark. 2002). Turizm gelişiminin kontrol altına alınmadığı bölgelerde çevresel, kültürel ve sosyal kaynaklar üzerinde sürekli bir baskının kurulması sonucu bu kaynakların aşırı zarar görmesi ve yok olması ile birlikte alanın turizm destinasyon özelliğini kaybetmesi gibi sonuçlar ortaya çıkabilmektedir (Maggi ve Fredella 2011).

Araştırmanın bu aşamasında çalışma alanında Nisan 2015May1s 2016 döneminde toplam 60 gün süresince yap1lan gözlemler, ilgili kişiler ve yöre halkı ile yapılan görüşmeler sonucu alanda tespit edilen, bir kısmının taşıma kapasitesinin üzerindeki yoğun kullanımlardan kaynaklandığı düşünülen bazı çevre sorunları aşağıda sunulmuştur.

- Traverten bölgesine düzenli ve sürekli kaynak suyunun aktarılmaması sonucu traverten oluşumu engellenmektedir.

- Dünya Miras Alanı'nın yakın çevresindeki diğer korunan alanlarla ilişkisinin olmamasından dolayı etkin koruma sağlanamamaktadır. 
- Denizli kentinin gelişmesine paralel olarak kentsel ve endüstriyel yerleşim alanlarının içerisinde kalan araştırma alanında iklim etkisi ile özellikle kış aylarında yaşanan hava kirliği ile çevredeki konaklama alanlarının sıcak su kaynaklarından kontrolsüz su almaları ve bunların kirletildikten sonra çevreye verilmesi travertenleri olumsuz etkilemektedir.

- Traverten alanı çevresindeki kontrolsüz yapılaşma (konut, işyeri, eğlence mekânları vb.) ve tamamen motorlu taşıtlara bağlı ulaşım olanakları nedeniyle gürültü rahatsız edici boyutlara ulaşmaktadır.

- Dünya Miras Alanı çevresindeki yapıların mimari bütünlüğ̈unün olmaması, kat boyutlarında farklılıklar, kitleboşluk dengesinin gözetilmemesi gibi yapılaşmaya bağlı olumsuzluklar yanında tabelaların gelişigüzel asılması, çöp toplama elemanlarının özensizliği, çevreye yayılmış katı atıklar gibi sorunlar da görsel kirliliğe neden olmaktadır.

- Koruma sınırı dışında bulunan ancak alanı doğrudan etkileyen plansız gelişmeler ile koruma alanı arasında tampon bölgenin bulunmaması, alan kullanımlarının arazi rantına bağlı olarak şekillenmesi gelecekte önüne geçilmesi zor sorunları ortaya çıkarabilecektir.

Korunan alanlarda uzun süreli sürdürülebilirliğin sağlanması için turizm ve rekreasyon faaliyetlerinin dikkatli bir şekilde planlanması, yönetilmesi ve izlenmesi gerekmektedir. Çünkü korunan alanlarda turizm doğal ve kültürel kaynakların kalitesine bağlı olarak gelişmektedir. $\mathrm{Bu}$ nedenle kaynaklar üzerindeki ziyaretçi etkileri çok dikkatli bir şekilde yönetilmeli, mümkünse doğrudan etkilerin azaltılmasına yönelik çalışmalar yapılmalıdır. Aksi durumda turizm ve rekreasyona bağlı olarak korunan alanlar üzerinde ortaya çıkabilecek olumsuz etkiler, alanın özgün değerlerinin yok olmasına ve kullanılamaz duruma gelmesine yol açabilir.

\section{Sonuç ve Öneriler}

Turizm çeşitleri yönünden zengin bir il olan Denizli, mevcut turizm türleri ile hem ülke ekonomisine hem de bölge ekonomisine önemli katkılar sunmaktadır. Ancak yapılan araştırmalar sonucu ildeki turizm faaliyetlerinin çoğunlukla çalışma alanının önemli bir bölümünü oluşturan Pamukkale/Hierapolis'te yoğunlaştı̆ğ ve günübirlik ziyaretlerle sınırlı olduğu görülmüştür. Ülkemizin en önemli turizm alanlarından olan Pamukkale/Hierapolis Dünya Miras Alanı'nda yürütülen bu çalışmada, turizmin ekonomik, sosyal ve kültürel yararlarının yanında ziyaretçi yoğunluğuna bağlı olumsuz etkilerinin olabileceği araştırılmıştır. Turizm amaçlı ziyaretçi yoğunluğu, özellikle hassas ekosistemlere sahip korunan alanlarda, alanın doğal ve kültürel yapısına verdiği zararlar nedeniyle birçok araştırmanın konusu olmuştur.

Pamukkale/Hierapolis Ören Yeri'nin giriş kapılarına göre günlük veya aylık ziyaret sayılarına ulaşılamadığından alanın yıllık ziyaret sayısı üzerinden değerlendirme yapılmıştır. Yaya giriş bölgesi olması dolayısıyla yapılan gözlemler sonucu en fazla ziyaretçinin traverten bölgesinden giriş yaptığ saptanmıştır. Hassas bir doğal yapıya sahip traverten bölgesinden alınan ziyaretçi sayısının sınırlandırılması, doğal özelliklerinin uzun süre korunması, alan üzerindeki baskıların azaltılması ve alanın gelecek nesillere aktarılması açısından önem taşımaktadır.

Ziyaretçilerin turistik alanlarda yol açtığı etkileri değerlendiren birçok araştırmada, gerçekleştirilen her rekreasyonel faaliyetin çeşidine göre alan üzerinde farklı düzeylerde etkilere yol açacağı belirtilmektedir. Bu nedenle Pamukkale/Hierapolis Dünya Miras Alanı'nda kültürel ve çevresel kaynakların hiç etkilenmeyeceği bir ziyaretçi seviyesinin ve alan kullanımının olduğunu söylemek oldukça güçtür. Ancak bu konuda yapılabilecek en önemli şey, mevcut etkinin veya ileride gelecek etkinin düzeyinin azaltılması yönünde önlemlerin alınmasıdır. Hem tarihi kültürel hem de doğal özellikleri nedeniyle uluslararası düzeyde öneme sahip olan çalışma alanında bozulmaların en aza indirgenmesi için bir takım öneriler geliştirilmiştir. Bunlar,

- Mevcut ziyaretçi sayısının takip edildiği sistemde günlük, aylık ve yıllık takipler yapılmaktadır. Ancak taşıma kapasitesi açısından daha detaylı bilgilere gereksinim duyulmaktadır. Ziyaretçilerin gün içerisinde kullandıkları alan ve yollardaki yoğunluk seviyelerinin izlenmesi ile anlık ziyaretçi sayısı hakkında bilgi sahibi olunmalıdır. Böylece alan içerisindeki ziyaretçi sayısının takibi ve alan içerisinde ne tür etkilerin yaşanabileceği takip edilebilir, yönetim modeline bu etkilerin azaltılması ile ilgili çözümler sunulabilir.

- Ziyaretçilerin alanda daha bilinçli hareket etmeleri için, ziyarete başlamadan önce, alanın doğal ve kültürel özellikleri hakkında bilgilendirilmeleri, alanın kaynaklarına zarar vermeden ziyaretlerini gerçekleştirmeleri açısından önem taşımaktadır.

- Ziyaretçilerin belirli büyüklükte gruplar halinde rehber eşliğinde alana alınması, ziyaretlerin daha bilinçli yapılmasını mümkün k1labilecektir.

- Ziyaretçi yoğunluğunun kontrol edilmesi amaciyla grup halindeki ziyaretçiler için önceden rezervasyon sisteminin oluşturulması ve bunun özellikle alanın kalabalık olmadığı zaman dilimlerine yayılması sağlanmalıdır.

- Koruma/kullanma dengesinin sağlanması ve alanın gelecek nesillere aktarılması açısından, aynı anda ören yerini gezecek olan ziyaretçi sayısının ne kadar olması gerektiğine karar verilmelidir. Burada özellikle alan yöneticilerinin ekonomik kaygıları dikkate almadan alanın sürdürülebilirliği açısından aynı anda kaç ziyaretçinin alana alınması gerektiğini belirlemesinde fayda vardır.

- Alanda ziyaret edilecek noktaların planlanması yolu ile ziyaretçilerin farklı bölgeleri kullanmaları sağlanarak belirli bölgelerde oluşabilecek yoğunluk engellenmelidir.

- Traverten alanlarına ziyaretçilerin havuzlarda biriken malcı yapıştırmaları hem travertenin yapısını bozmakta, hem de görsel kirliliğe neden olmaktadır. $\mathrm{Bu}$ nedenle mevcut kalıntıların temizlenmesi ve ziyaretçilerin bu konuda hassasiyet göstermeleri konusunda uyarıların yapılması gerekmektedir.

Sonuç olarak, Pamukkale/Hierapolis Dünya Miras Alanı'nda Fiziksel Taşıma Kapasitesi aşımı hipotezi kısmen doğrulanmıştır. Alanda yapılan Sosyal Taşıma Kapasitesi (2 kat) ve Fiziksel Taşıma Kapasitesi (\%10) hesaplamaları sonucunda mevcut ziyaretçi sayısının fazla olduğu ve alanda yaşanan sorunların ziyaretçi sayısına da bağlı olduğu anlaşılmaktadır. Ancak kentin son yıllardaki nüfus artışı, yapılaşma hızı, kent içi ve yakınındaki sanayi tesisleri, ulaşım ağlarındaki gelişmeler, tarımsal etkinliklerden kaynaklanan faaliyetler Pamukkale/Hierapolis Dünya Miras Alanı üzerinde doğrudan veya dolaylı etkili olmaktadır. Bu etkiler alan içerisindeki turizm ve rekreasyon faaliyetlerinden kaynaklanan etkiler ile birleşince hissedilen etki düzeyi artmaktadır. Bu nedenle Pamukkale/Hierapolis Dünya Miras Alanı içerisindeki sorunların ortadan kaldırılması için, kent ve Pamukkale Özel 
Çevre Koruma Bölgesi ile ilgili tüm planların dikkate alınması gerekmektedir.

\section{Teşekkür}

Yüksek Lisans tez çalışması kapsamında FYL-2016-1052 proje no ile bu araştırmayı destekleyen Akdeniz Üniversitesi Bilimsel Araştırma Projeleri Yönetim Birimi’ne teşekkür ederiz.

\section{Kaynaklar}

Ceballos-Lascuráin H (1996) Tourism, Ecotourism and Protected Areas: The State of Nature-Based Tourism around the World and Guidelines for Its Development. IUCN Publications, Cambridge, 301. http://dx.doi.org/10.2305/iucn.ch.1996.7.en. Erişim 10 May1s 2015.

Chen H, Chen C, Chang C (2014) The construction and application of a carrying capacity evaluation model in a national park. Stoch Environ Res Risk Assess. 28: 1333-1341.

Clarke AL (2002) Assessing the carrying capacity of the Florida Keys. Journal of Population and Environment, 23(4): 405-418.

Cole D (2004) Carrying capacity and visitor management: facts, values and the role of science, protecting our diverse heritage: the role of parks. Protected Areas and Cultural Sites, 43-46.

Çevre ve Şehircilik Bakanlığı http://www.csb.gov.tr/gm/tabiat/index.php?Sayfa=sayfa\&Tur=web menu\&Id=19. Erişim 10 Nisan 2014.

Denizli İl Kültür ve Turizm Müdürlüğü (2015) http://www.pamukkale.gov.tr/tr/Antik-Kentler Erişim 09 Mayıs 2015.

Doğa Koruma ve Milli Parklar Genel Müdürlüğü (2014) http://www.milliparklar.gov.tr/Anasayfa/istatistik.aspx?sflang=tr Erişim 10 Mayıs 2015.

DÖSIMM (2016) T.C. Kültür ve Turizm Bakanlığı Döner Sermaye İşletmesi Merkez Müdürlüğü. http://www.muze.gov.tr/tr/muzeler/pamukkale-hierapolis-orenyeri Erişim 10 Ocak 2016.

Eagles PFJ, Mccool SF, Haynes CD (2002) Sustainable tourism in protected areas guidelines for planning and management. World Commission on Protected Areas (WCPA), Best Practice Protected Area Guidelines Series No: 8.

Fleishman L, Feitelson E (2009) An application of the recreation level of service approach to forests in Israel. Landscape and Urban Planning 89: 86-97.

Göktuğ TH (2011) Dilek yarımadası büyük menderes deltası milli parkı'nın rekreasyonel taşıma kapasitesinin belirlenmesi üzerine bir araştırma. Doktora Tezi, Atatürk Üniversitesi Fen Bilimleri Enstitüsü Peyzaj Mimarlığı Anabilim Dalı, Erzurum.

Gündüz S, Akpınar N (2002) Koruma-kullanım ilkeleri çerçevesinde Beynam Muhafaza Ormanı'nın rekreasyonel taşıma kapasitesinin saptanması üzerine bir araştırma. Tarım Bilimleri Dergisi, 8(4): 344-351.

Haas GE (2002) Visitor capacity on public land and water: making better decision, national recreation and park association, Ashburn, Virginia.

http://www.fs.fed.us/cdt/carrying_capacity/visitor_capacity_on_pu blic_lands_and_waters_making_better_decisions_2006.pdf Accessed 03 May, 2015.

Jurado EN, Damian IM, Morales A (2013) Carrying capacity model applied in coastal destinations. Annals of Tourism Research, 43: $1-19$.

Jurincic I (2005) Carrying Capacity assessment of Slovene Istria for tourism. Journal of Sustainable Development and Planning II, 1: $725-733$.
Kurhade SY (2013) Methodological framework for evaluation of tourism carrying capacity of eco sensitive region. International Journal of Innovative Research in Science, Engineering and Technology, 2 (3): 781-786.

Kültür ve Turizm Bakanlığı http://www.kulturportali.gov.tr/turkiye/denizli/ kulturenvanterisit/hierapolis-pamukkale-antik-kenti-i-ve-iii-derecearkeolojik-sit-alani Erişim 09 Mayıs 2015.

Lawson S, Manning R, Valliere W, Wang B (2003) Proactive monitoring and adaptive management of social carrying capacity in arches national park: an application of computer simulation modeling. Journal of Environmental Management, 68: 305-313.

Leujak W, Ormond R (2007) Visitor perceptions and the shifting social carrying capacity of South Sinai's Coral Reef. Envorin Manage 39: 472-489.

Lindberg K, McCool S, Stankey G (1996) Rethinking carrying capacity, research notes and reports, PII: S0160-7383 (96) 00075-8.

Maggi E, Fradella FL (2011) The carrying capacity of a tourism destination: the case of a Coastal Italian City. https://ideas.repec.org/p/wiw/wiwrsa/ersa10p576.html\#cites Accessed 03 February, 2015.

Manning R, Wang B, Valliere W, Lawson S, Newman P (2002). Research to estimate and manage carrying capacity of a tourist attraction: a study of Alcatraz Island. Journal of Sustainable Tourism, 10: 5, 388-404.

Manning R, Valliere W, Wang B, Lawson S, Newman P (2003). Estimating day use social carrying capacity in Yosemite National Park. Lesisure/Loisir, Vol. 27: 77-102.

Manning R (2007) Parks and carrying capacity commons without tragedy. Island Press, Washington, USA, pp. 328.

McCool SF, Lime DW (2001) Tourism carrying capacity: tempting fantasy or useful reality? Journal of Sustainable Tourism, 9(5): 372-388.

Müderrisoğlu H (2002) Açıkhava rekreasyonunda taşıma kapasiteleri: rekreasyonel kullanım ilişkilerinin incelenmesi. Doktora Tezi, İstanbul Üniversitesi Fen Bilimleri Enstitüsü Peyzaj Mimarlığı Anabilim Dalı, İstanbul.

Neufert E (2012) Yap1 Tasarımı. Beta Yayınları, 35. Bask1. ISBN: 6053339571.

Prato T (2001) Modeling carrying capacity for national parks. Ecological Economics, 39: 321-331, Colombia.

Prato T (2009) Fuzzy adaptive management of social and ecological carrying capacities for protected areas. Journal of Environmental Management, 90 pp. 2551-2557.

Pulido A (1972) Estadistica y Techicas de Investipacion Social. Ediciones Anaya, Madrid.

Resmi Gazete (1990) http://www.resmigazete.gov.tr/arsiv/20702.pdf Erişim 11 Ocak 2015.

Rios-Jara E, Galvan-CM, Rodriguez-Zaragoza FA, Lopez-Uriarte E, Munoz-Fernandez VT (2013) The tourism carrying capacity of underwater trails in Isabel Island National Park, Mexico. Environmental Management. 52: 335-347.

Salerno F, Viviano G, Manfredi EC, Caroli P, Thakuri S, Tartari G, (2013) Multiple Carrying Capacities from a Management-Oriented Perspective to Operationalize Sustainable Tourism in Protected Areas. Journal of Environmental Management, 128 (2013) 116125.

Saveriades A (2000) Establishing the social tourism carrying capacity for the tourist resorts of the east coast of the Republic of Cyprus. Journal of Tourism Management, 21: 147-156.

Sayan MS, Ortaçeşme V, Karagüzel O, Şahin T, Yıldırım E, Avcı Ü (2005) Termessos (Güllükdağı) Milli Parkı'nda rekreasyonel taşıma kapasitesinin belirlenmesi. Türkiye Bilimsel ve Teknolojik 
Araştırma Kurumu, Tarım, Ormancılık ve Veterinerlik Araştırma Grubu, Proje No: TOGTAG-3197, Ankara.

Silva CP, Alves F, Rocha R (2007) The management of beach carrying capacity: the case of Northern Portugal. Journal of Coastal Research, SI 50 (Proceedings of the 9th International Coastal Symposium), pp. 135-139. Gold Coast, Australia, ISSN 0749.0208.

Simon FJG, Narangajava Y, Marqués DP (2004) Carrying capacity in the tourism industry: a case study of Hengistbury Head. Journal of Tourism Management, 25: 275-283.

Soylu Y (2013) Turistik destinasyonlarda taşıma kapasitesi: Gelibolu Yarımadası Tarihi Milli Parkı Örneği. Yüksek Lisans Tezi, Çanakkale On Sekiz Mart Üniversitesi Sosyal Bilimler Enstitüsü Turizm İşletmeciliği Anabilim Dalı, Çanakkale.

Sterl P, Wagner S, Arnberg A (2004) Social carrying capacity of canoeists in Austria's Danube Floodplains National Park. Working Papers of the Finish Forest Research Instute 2: 256-263. http://www.metla.fi/julkaisut/workingpapers/2004/mwp002.htm.

Tarrant M, English DBK (1996) A crowding-based model of social carrying capacity: applications for Whitewater Boating Use. Journal of Leisure Research, Vol 28, No. 3, pp. 155-168.

Tokmak C (2008) Sürdürülebilir turizm açısından tasıma kapasitesi: Topkapı Sarayı Örneği. Doktora Tezi, Gazi Üniversitesi Eğitim Bilimleri Enstitüsü Turizm İşletmeciliği Eğitimi Anabilim Dalı, Ankara.
Turton SM (2005) Managing environmental impacts of recreation and tourism in rainforest of the wet tropics of Queensland World Heritage Area. Geographical Reseach 43(2): 140-151.

UNEP (1997) Guidelines for carriyng capacity assessment for tourism in Mediterranean Coastal Areas. Priority Actions Programme Regional Activity Centre, Split (Croatia).

UNESCO (2014) United Nations Educational, Scientific and Cultural Organization http://whc.unesco.org/en/list/485/ Accessed 20 June, 2015.

Yang T, Huang I, Huang E, Huang L (2014) A comparison of visitors' characteristics, traveling motivations, recreational experiences, and attitudes toward recreational carrying-capacity controls between peak and off-peak season. Journal of Forest Science, 29(1): 17-31, Taiwan.

Yıldırım U (2012) Plaj ve deniz rekreasyon alanlarında ziyaretçi taşıma kapasitelerinin belirlenmesi ve plaj yönetiminde LAC modeli uygulaması. Yüksek Lisans Tezi, Akdeniz Üniversitesi Fen Bilimleri Enstitüsü, Antalya.

Zacarias DA, Williams AT, Newton A (2011) Recreation carrying capacity estimations to support beach management at Praia de Faro, Portugal. Applied Geography 3: 1075-1081. 